\title{
Obstructive Sleep Apnea Syndrome
}

\author{
Suresh Menon
}

\subsection{Introduction}

Obstructive sleep apnea (OSA) is a condition that affects $2-4 \%$ of the adult population. This disease has reached a proportion of increasing importance due to its neurological and cardiological consequences. Abnormal pharyngeal anatomy and altered activity of the upper airway musculature dilator physiology are primarily responsible for the collapse of the pharyngeal walls during sleep.

\subsection{Definition}

OSA is defined by the occurrence of daytime sleepiness, loud snoring, witnessed breathing interruptions, or awakenings due to gasping or choking in the presence of at least five obstructive respiratory events (apneas, hypopneas, or respiratory effort-related arousals) per hour of sleep [1].

When OSA is accompanied by excessive daytime sleepiness, it is termed Obstructive Sleep Apnea Syndorme.

The common terms that are used in OSA are apnea, hypopnea, apnea hypopnea index (AHI), and respiratory distress index (RDI) [2].

1. Apnea is the cessation of airflow, exceeding 10 seconds.

2. A hypopnea is reduced airflow exceeding 10 seconds accompanied by a desaturation of $3 \%$ or more of oxygen and/or electroencephalographic evidence of arousal.

3. The apnea hypopnea index (AHI) is the number of apneas and hypopneas per hour of sleep. A value of 5-15 represents mild sleep apnea, 15-30 moderate, and greater than 30 , severe.

4. Respiratory distress index (RDI) includes other parameters in addition to apnea and hypopnea like respiratory effort-related arousals (RERAs). This is characterized by

S. Menon $(\bowtie)$

Department of Oral and Maxillofacial Surgery, Vydehi Institute of

Dental Sciences and Research Centre, Bangalore, India increasing respiratory effort for 10 or more seconds leading to an arousal from sleep but not meeting the criteria of an apnea or hypopnea [3].

\subsection{Etiopathogenesis}

The upper airway is a flexible structure consisting of muscle and fat tissue and is usually only passively supported by bones. Therefore, it can be easily influenced by soft tissue factors like fat deposition in the parapharyngeal structures, edema/inflammation of the parapharyngeal region, hypertrophy of adenotonsillar tissues, or enlarged tongue.

The primary actor in the pathophysiology of OSA is the narrow, floppy upper airway. There is increased resistance of the upper airway due to anatomic factors that creates a negative airway pressure. This results in impaired function of airway-dilating muscles, thus increasing collapsibility. During sleep, the loss of skeletal muscle tone narrows the upper airway, making it floppier, especially during rapid eye movement (REM) sleep when muscle relaxation is intense. This results in two significant actions:

- The turbulent flow patterns that occur lead to vibration of structures causing snoring.

- The pharynx collapses due to the Bernoulli effect. This causes an obstruction which could be partial or complete. This tends to persist until sleep is interrupted and muscle tone is restored. These interruptions usually last less than 15 seconds, and the individual is unaware of them. Sometimes, the obstruction results in an awakening, and the individual complains of suddenly waking with a snort or a snore. Breathing is reestablished on arousal, and after a few breaths deeper sleep resumes with repetition of the cycle during muscle relaxation. 
Additional factors that can increase the severity of upper airway resistance during sleep are mouth opening or a supine posture which allows the gravitational forces to push the tongue and soft palate back. Upper airway resistance can occur anywhere from the nasopharynx to the hypopharynx but primarily involves the oropharynx (Fig. 71.1).

\subsection{Risk Factors for OSA}

\subsubsection{Age}

The disease prevalence increases steadily with age and reaches a stable level after the age of 60 years. The probable explanations for the age-related increase in prevalence include increased fat deposition in the parapharyngeal area, soft palate lengthening, etc.

\subsubsection{Excess Body Weight}

Body weight is an important risk factor for OSA, and studies have endorsed the positive effects of dieting and surgical weight loss on reducing OSA. Body weight increase can affect normal upper airway mechanics during sleep through:

1. Reduction of upper airway by increased parapharyngeal fat deposition.

2. Changing neural compensatory mechanisms that maintain patency of airway.

3. Instability of respiratory control system.

4. Reduction in functional residual capacity.

\subsubsection{Gender}

It is an established fact that men are more vulnerable than women toward developing OSA. The differences exist not only in prevalence but also in polysomnographic characteristics of sleep and breathing patterns. Women were seen to have a lower AHI in non-rapid eye movement (non-REM) sleep. Disordered breathing events in women have a shorter duration and are associated with less oxyhemoglobin desaturation than in men.

\subsubsection{Craniofacial Anatomy}

The mechanical properties of the upper airway and the tendency to collapse during sleep can be influenced by both hard and soft tissues in the region. Findings in the craniofacial region like large tongue or soft palate, reduced mandibular size, or tonsillar hypertrophy in addition to inferiorly placed hyoid, maxillary, and mandibular retropositioning can narrow upper airway dimensions and leading to episodes of apneas and hypopneas during sleep.

\subsubsection{Familial and Genetic Predisposition}

Inheritance and familial factors also play a major role in OSA. First-degree relatives of OSA patients seem to be at risk more likely than others. The familial susceptibility tends to increase directly with the number of affected relatives.

Heredity and genetic factors also have been found to have a role in determining the volume of the lateral parapharyngeal

Fig. 71.1 Areas causing OSA

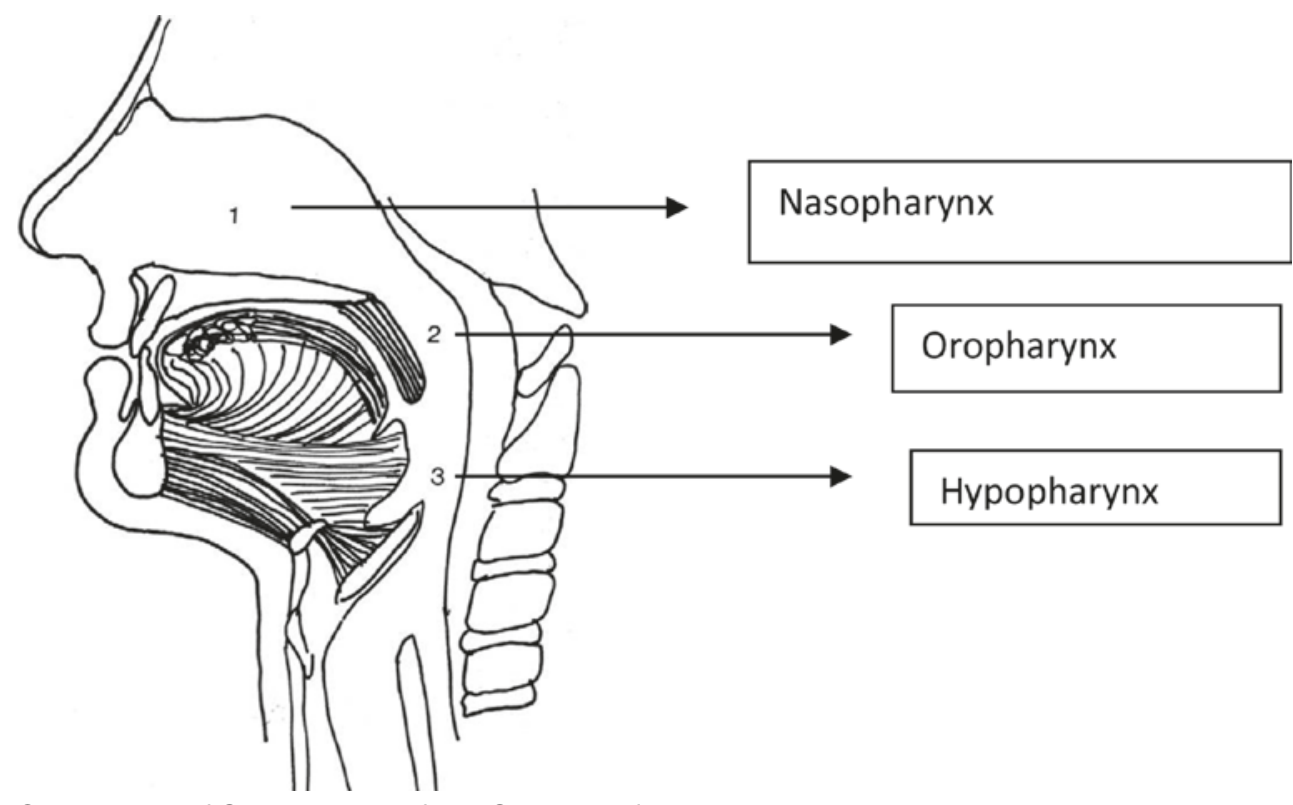


walls, tongue, and total soft tissue structures. A detailed family history can help in identifying those that have the disorder but remain undiagnosed.

\subsubsection{Smoking and Alcohol Consumption}

Cigarette smoking and alcohol are also possible risk factors for obstructive sleep apnea. Airway inflammation can occur due to cigarette smoke that could modify the properties of upper airway and increase its collapsibility during sleep. Alcohol consumption before sleep increases upper airway collapsibility and the precipitate apneic and hypopneic episodes during sleep. Another effect of alcohol is to inhibit respiratory motor output to the upper airway, causing hypotonia of the oropharyngeal muscles.

\subsubsection{Medical Comorbidity}

There is enough evidence to suggest that OSA can be a factor in the development of hypertension, coronary artery disease, congestive heart failure, and stroke [4].

OSA is also associated with diabetes mellitus, Therefore, diagnosing the condition and intervening early could directly or indirectly enhance glycemic control [5]. The role of positive airway pressure (PAP) therapy could result in reduced day time fatigue, better physical activity, resulting in improved metabolic control.

\subsection{Clinical Sequelae [6]}

\subsubsection{Endocrine and Metabolic Effects}

The central effects of sleep fragmentation and hypoxemia have been seen to induce a reversible neuroendocrine defect in growth hormone and testosterone secretion. This may explain impaired growth seen in children with upper airway obstruction which seems to get better after adenotonsillectomy.

\subsubsection{Neuropsychological and Social Consequences}

The classic feature of OSA prevalent as excessive daytime sleepiness may lead to both impaired work performance and driving. OSA patients seem to perform poorly on psychometric tests, and improvement has been seen after nasal CPAP therapy.

\subsubsection{Cardiovascular Sequelae}

There are two serious consequences of OSA involving the cardiovascular system. Initially acute cardiovascular changes occur during an apnea. This is followed by more chronic cardiovascular conditions like hypertension, myocardial infarction, stroke, and death.

\subsection{Epidemiology $[7,8]$}

OSA has no specific age predilections, but a study by Young et al. estimated the prevalence in middle age to be $4 \%$ for men and $2 \%$ for women. Their study estimated that 1 of every 5 adults has at least mild OSA and 1 of every 15 has at least moderate OSA.

\subsection{Diagnosis [1]}

A detailed study of clinical signs and symptoms established during a comprehensive sleep evaluation and findings identified by sleep testing lead to the diagnosis of OSA.

\subsubsection{History and Physical Examination}

The diagnosis of OSA begins with a sleep history in one of three settings:

1. Part of routine health maintenance evaluation.

2. Part of an evaluation of symptoms of OSA.

3. Part of the comprehensive evaluation of patients at high risk for OSA.

Of the available, the Epworth sleepiness scale (ESS) (Table 71.1) is a popular subjective-based self-assessment of sleepiness that determines the degrees of sleepiness [9].

When scores are greater than 10, further investigations are recommended. However as about $10 \%$ of the population have a score of 11 or more, this score should be complemented by a narrative confirmation of intrusive somnolence.

\subsubsection{Polysomnography (PSG)}

This is an overnight sleep study monitored by a sleep technologist and is considered the "gold standard" in sleep medicine (Fig. 71.2). The physiologic parameters measured during PSG include simultaneous monitoring of 
Table 71.1 Epworth sleepiness scale

\begin{tabular}{|c|c|}
\hline Name: & Date: \\
\hline Age: & Sex: \\
\hline \multicolumn{2}{|c|}{$\begin{array}{l}\text { How likely are you to doze off or fall asleep in the following } \\
\text { situations, in contrast to feeling just tired? }\end{array}$} \\
\hline \multicolumn{2}{|c|}{$\begin{array}{l}\text { Use the following scale to choose the most appropriate number for } \\
\text { each situation: }\end{array}$} \\
\hline \multicolumn{2}{|c|}{ 0—Would never doze } \\
\hline \multicolumn{2}{|l|}{1 -Slight chance of dozing } \\
\hline \multicolumn{2}{|l|}{ 2-Moderate chance of dozing } \\
\hline \multicolumn{2}{|l|}{ 3-High chance of dozing } \\
\hline Situation & $\begin{array}{l}\text { Chance of } \\
\text { dozing }(0-3)\end{array}$ \\
\hline 1. Sitting and reading. & ---------- \\
\hline 2. Watching TV. & ---------- \\
\hline $\begin{array}{l}\text { 3. Sitting inactive in a public place like theatre/ } \\
\text { meeting. }\end{array}$ & ---------- \\
\hline $\begin{array}{l}\text { 4. As a passenger in a car for an hour without } \\
\text { break. }\end{array}$ & ---------- \\
\hline $\begin{array}{l}\text { 5. Lying down to rest in the afternoon when } \\
\text { circumstances permit. }\end{array}$ & ---------- \\
\hline 6. Sitting and talking to someone. & ---------- \\
\hline 7. Sitting quietly after lunch without alcohol. & ---------- \\
\hline $\begin{array}{l}\text { 8. In a car, while stopped for a few minutes in } \\
\text { traffic. }\end{array}$ & ---------- \\
\hline
\end{tabular}

brain wave activity continuously, eye movements, muscle activity of the legs and mandible, body position, heart rate and rhythm, blood pressure, snoring, and respiratory activity including breathing patterns and oxygen saturation. A detailed analysis of these can reveal apneic, hypopneic activities, etc.

Presence of obesity or signs of upper airway narrowing should also be documented.

\section{Patients at High Risk for OSA and Who all should be evaluated for OSA Symptoms [1]}

1. Obesity (BMI $>35)$.

2. Congestive heart failure.

3. Atrial fibrillation.

4. Treatment refractory hypertension.

5. Type 2 diabetes.

6. Nocturnal dysrhythmias.

7. Stroke.

8. Pulmonary hypertension.

9. High-risk driving populations.

10. Alcohol consumption.

11. Preoperative for bariatric surgery.

\section{OSA Symptoms That Should Be Evaluated During a Comprehensive Sleep Evaluation}

1. Witnessed apneas.

2. Snoring.

3. Gasping/choking at night.

4. Excessive sleepiness not explained by other factors.

5. Non refreshing sleep.

6. Total sleep amount.

7. Sleep fragmentation/maintenance insomnia.

8. Nocturia.

9. Morning headaches.

10. Decreased concentration.

11. Memory loss.

12. Decreased libido.

13. Irritability.

\subsubsection{Imaging Aids}

\subsubsection{Cephalometrics}

There is a plethora of imaging aids to help diagnose and plan the management of OSA. Cephalometrics has been the oldest imaging modality in the diagnosis of OSA. However, its role in quantification of the pharyngeal volume is controversial as the image that is two-dimensional is used to evaluate a three-dimensional structure [3].

It is a known fact that the lateral pharyngeal wall collapse has a bigger influence on severe sleep apnea than retropalatal and retrolingual collapse as studied with dynamic MRI, and this would not appear evident on a lateral cephalogram [10]. Another shortcoming of lateral cephalograms is that they are taken with the patient upright and awake and therefore do not characterize the asleep or supine airway.

Cephalometric images however have other advantages that can be used to predict OSA. It can be used to measure the upper airway length (UAL) (Fig. 71.3). UAL is significantly longer in OSA patients due to the relation between UAL and airflow resistance. Since the part of the airway is primarily composed of the soft tissues compared to the more rigid, cartilaginous, subglottic airway, this region may predispose to collapse. Studies have proved that male patients with UAL $\geq 72 \mathrm{~mm}$ have an eightfold increase in the probability of OSA while females with UAL $\geq 62 \mathrm{~mm}$ have a fivefold increase in OSA probability [11]. 


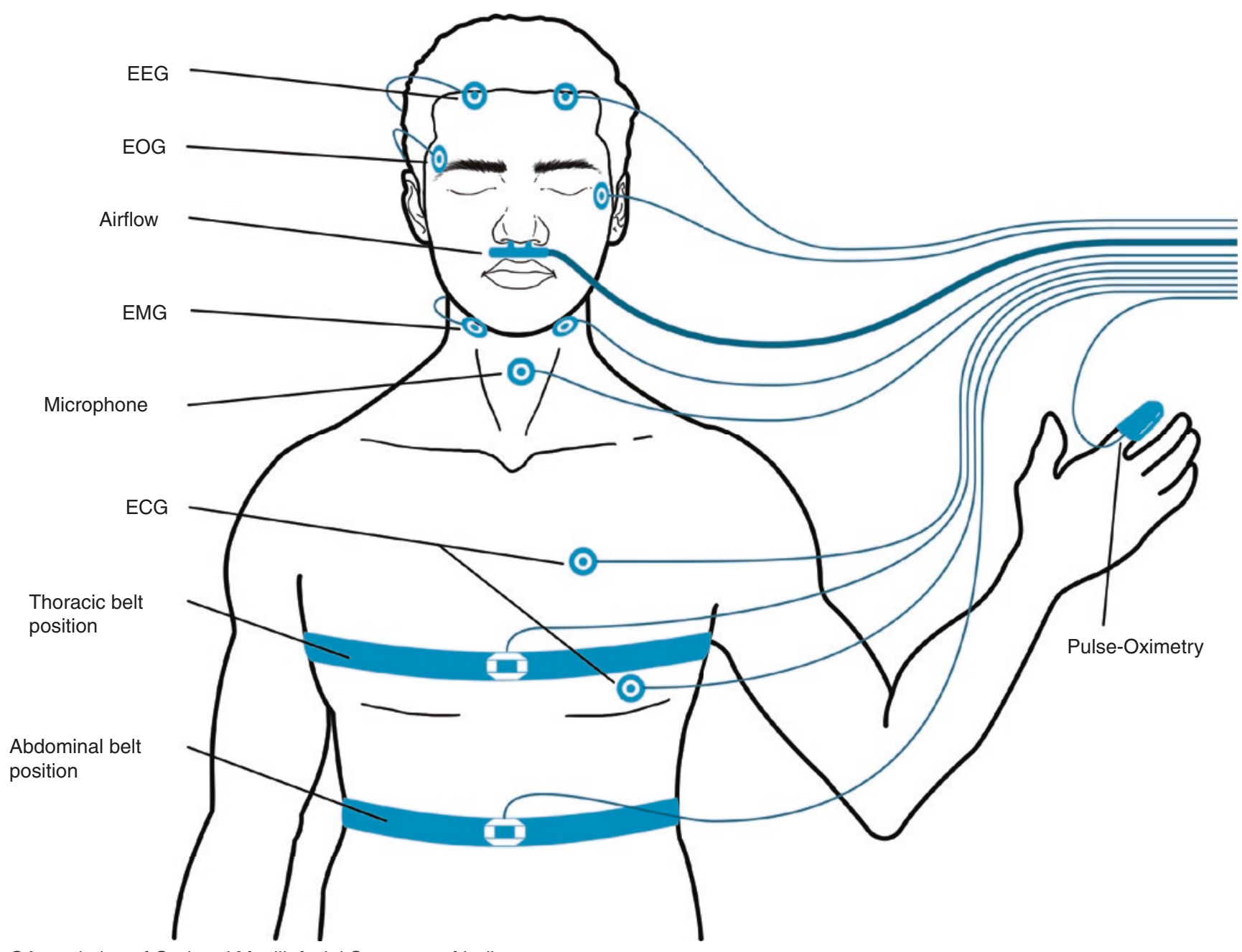

CAssociation of Oral and Maxillofacial Surgeons of India

Fig. 71.2 Polysomnography leads and parameters. EEG Electroencephalogram, EOG Electrooculography, EMG Electromyography, ECG Electrocardiography

Cephalometrics can also be used to predict the success in multilevel phase I therapy for patients. Skeletal class II patients with a more retrognathic mandible are poor responders. Other patients who could be poor responders include those with hyperdivergent vertical pattern with a larger mandibular plane angle, longer lower facial height, and steeper occlusal plane [9].

\subsubsection{Dynamic Upper Airway Imaging [12]}

Dynamically assessment of the level of upper airway obstruction in OSA patients will allow targeted intervention and allow planning a specific surgical procedure by allowing a delineation of the site and specifying degree and pattern of obstruction. It can also be used to exclude pathology like tumors. Dynamic sleep MRI and drug-induced sleep CT scan characterize the airway in OSA with the advantage of ability to evaluate the airway in a multiplane fashion in the sleeping state or a simulated sleep state.

Drug-induced sleep endoscopy (DISE) is an alternative to conventional endoscopy with the goal of more accurately representing patterns of collapse during the sleeping state.

\subsubsection{Acoustic Reflex Ion Test}

In this test, sound waves are projected into the airway and are reflected into the tube to a computer which creates an image that determines the location of obstruction. This can also predict the effect of mandibular advancement and protrusion on upper airway. 


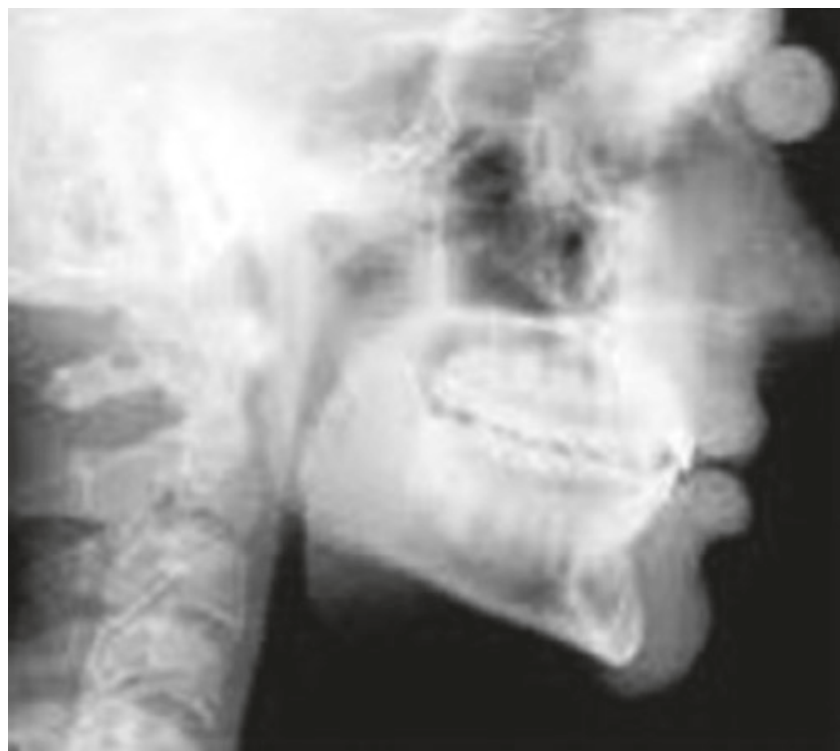

CAssociation of Oral and Maxillofacial Surgeons of India

Fig. 71.3 Narrowing of oropharynx and long upper airway length in OSA

\subsection{Clinical Features (Tables 71.2 and 71.3)}

\subsection{Treatment Modalities}

OSA is a chronic condition that would require multidisciplinary management over a long period of time. There is a myriad of options to treat the condition ranging from behavioral to medical to surgical options. The success of treatment would have to ensure the voluntary active participation of the patient.

\subsubsection{Positive Airway Pressure [13]}

Continuous positive airway pressure (CPAP) is usually the first line of treatment for OSA. It works on the principle of binding the upper airway in an open position to improve patency during sleep (Fig. 71.4).

This was first described by Sullivan [14] in 1981. The pneumatic splinting action is effective in reducing the AHI. PAP may be delivered in either continuous (CPAP), bilevel (BPAP), or auto titrating (APAP) modes. CPAP is the first line of treatment for moderate to severe OSA and may be used occasionally in mild OSA. CPAP has also found to be effective as an adjunctive therapy to alter blood pressure in OSA patients having hypertension.

Some of these patients may elicit intolerance for CPAP therapy. In these cases, BPAP, pressure relief, or APAP can be considered as an alternative. In addition to its splinting
Table 71.2 Symptoms of OSAS

\begin{tabular}{|l|l|}
\hline Adult & Children \\
\hline Heavy snoring & Snoring \\
\hline Excessive daytime sleepiness & Restless sleeping \\
\hline Apneas & Somnolence \\
\hline $\begin{array}{l}\text { Sudden awakenings with } \\
\text { 'choking' }\end{array}$ & $\begin{array}{l}\text { Aggression/behavioral } \\
\text { problems }\end{array}$ \\
\hline Accidents related to sleepiness & Hyperactivity \\
\hline Poor memory/concentration & Odd sleeping postures \\
\hline Delirium & Frequent coughs/colds \\
\hline Gastroesophageal reflux & \\
\hline Mood/personality changes & \\
\hline Nocturnal sweating & \\
\hline Restlessness during sleep & \\
\hline Nocturia & \\
\hline Enuresis & \\
\hline Dry mouth on awakening & \\
\hline Nocturnal or morning headache & \\
\hline Impotence & \\
\hline Nocturnal epilepsy &
\end{tabular}

Table 71.3 Signs of OSAS

Edematous soft palate or uvula

Long soft palate and uvula

Decreased oropharyngeal dimensions

Nasal obstruction

Maxillary hypoplasia

Retrognathia

Central adiposity/increased neck circumference

Hypertension and other cardiovascular consequences

action, CPAP increases vagal tone, cardiac output, and stroke volume and decreases systemic vascular resistance, and there is reduced risk of cardiovascular mortality.

Compliance with nasal CPAP (nCPAP) ranges from 50 to $89 \%$ [15]. Reasons for noncompliance are usually due to tolerance problems like dry mouth, conjunctivitis, rhinorrhea, skin irritation, pressure sores, nasal congestion, and epistaxis. Other less common causes of noncompliance include aerophagia, chest discomfort, and bed partner intolerance or psychological problems arising from lack of motivation, claustrophobia, and anxiety.

Though there is no established known lower limit of nightly use below which nCPAP therapy is ineffective, it is suggested that $3.4 \mathrm{~h}$ per night of nCPAP use may be adequate to improve cognitive function and quality of life.

\subsubsection{Behavioral Strategies [16]}

Behavioral strategies have also been used as treatment methods in OSA. These include weight loss, regular exercise, positional therapy, and sleep hygiene which involves alcohol abstinence and consumption of sedatives before sleep.

Sleep position while supine can decrease the lateral upper airway dimensions, particularly while in the supine position. 


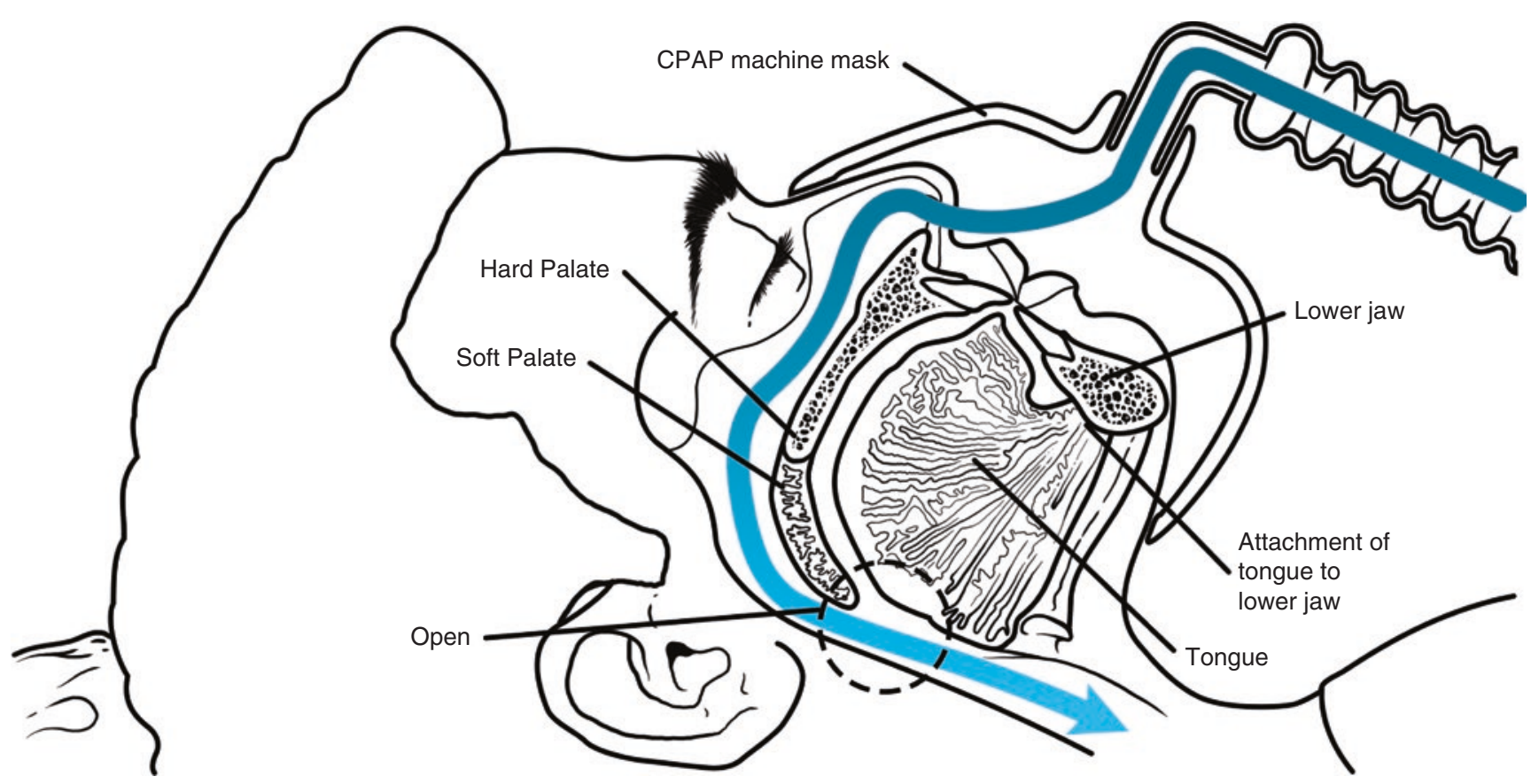

CAssociation of Oral and Maxillofacial Surgeons of India

Fig. 71.4 CPAP usage

Therefore, in positional therapy, the patient is kept in a nonsupine position.

\subsubsection{Oral Appliances [17]}

The primary role of oral appliances (OAs) is to enlarge the posterior oropharyngeal airway space, leading to reduction of chances of the upper airway collapsing during sleep. They are ideally indicated in mild and moderate cases of OSA who are noncompliant/poorly compliant to nasal CPAP. Oral appliances are of two types: tongue retaining or mandibular repositioning.

- Tongue retaining devices [18]: These appliances position the tongue anteriorly by means of negative pressure and are indicated for patients who have few teeth or are edentulous, have macroglossia, or who are unable to adequately advance their mandible. The result is increase of the volume of the upper airway.

- Mandibular repositioning devices (MRD) [19]: As the name suggests, they reposition the mandible and structures attached to it like the tongue and hyoid bone anteriorly, thus increasing the upper airway dimensions in both sagittal and transverse planes, especially at the level of the velopharynx (Fig. 71.5). The appliances completely cover the maxillary and mandibular dentition and hold the mandible forward with respect to the resting position. The amount of advancement is titrated depending on the symptoms not exceeding $80 \%$ of the patient's maximum protrusive capacity. This is followed by polysomnography to check the efficacy.

It is mandatory for patients using MRD to have adequate number of teeth to seat the appliance. There should not be any deleterious TMJ disorder, and the patients should have an adequate range of jaw motion and adequate manual dexterity and should be motivated to use the appliance.

The MRD device is customized and the material used is flexible polyamide.

In general, OAs are either titratable or non-titratable. Titratable OAs permit varying amounts of mandibular protrusion. Non-titratable OAs hold the mandible in a single protrusive position without any possibility to change the position during treatment. Some of the non-titratable devices are a simple splint, bionator, Karwatsky activator, or Herbst appliance [20].

\subsubsection{Surgical Treatment of Obstructive Sleep Apnea [21] (Table 71.4)}

Surgical procedures to correct or treat OSA essentially provide site-specific treatment to increase airway size and decrease airway resistance, thus reducing the effort required in breathing. The site of obstruction is specific to each patient and is as unique as fingerprints. Therefore, one needs to know which the most appropriate procedure is to guarantee success. Since no single factor is predictive of OSA, the significance of a thorough physical examination and imaging to 


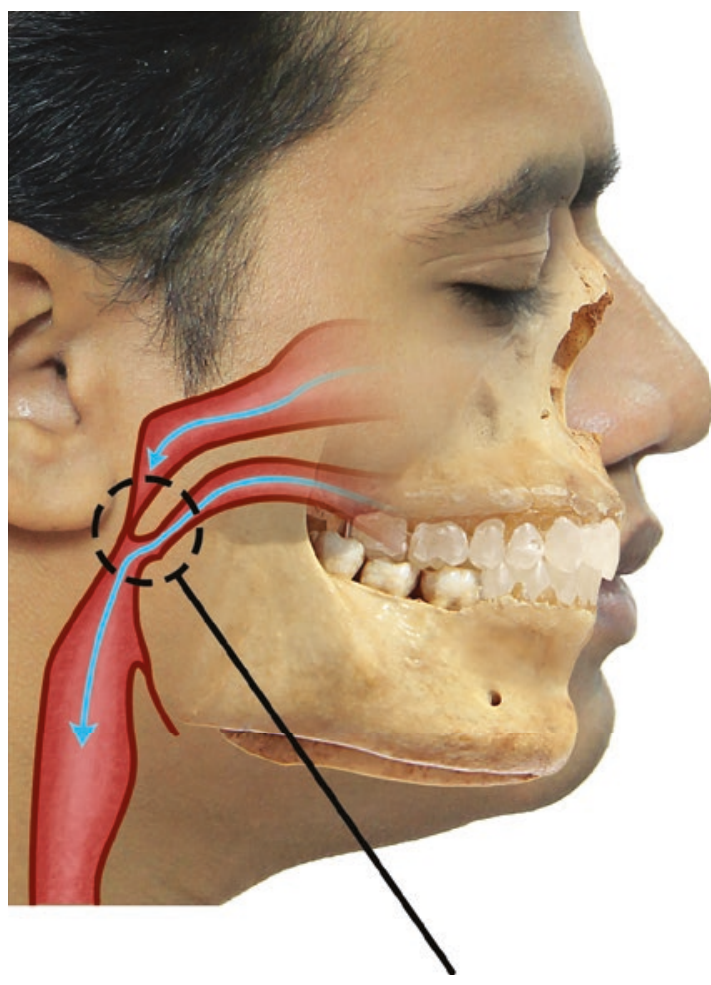

During sleep there is restricted airway space

CAssociation of Oral and Maxillofacial Surgeons of India

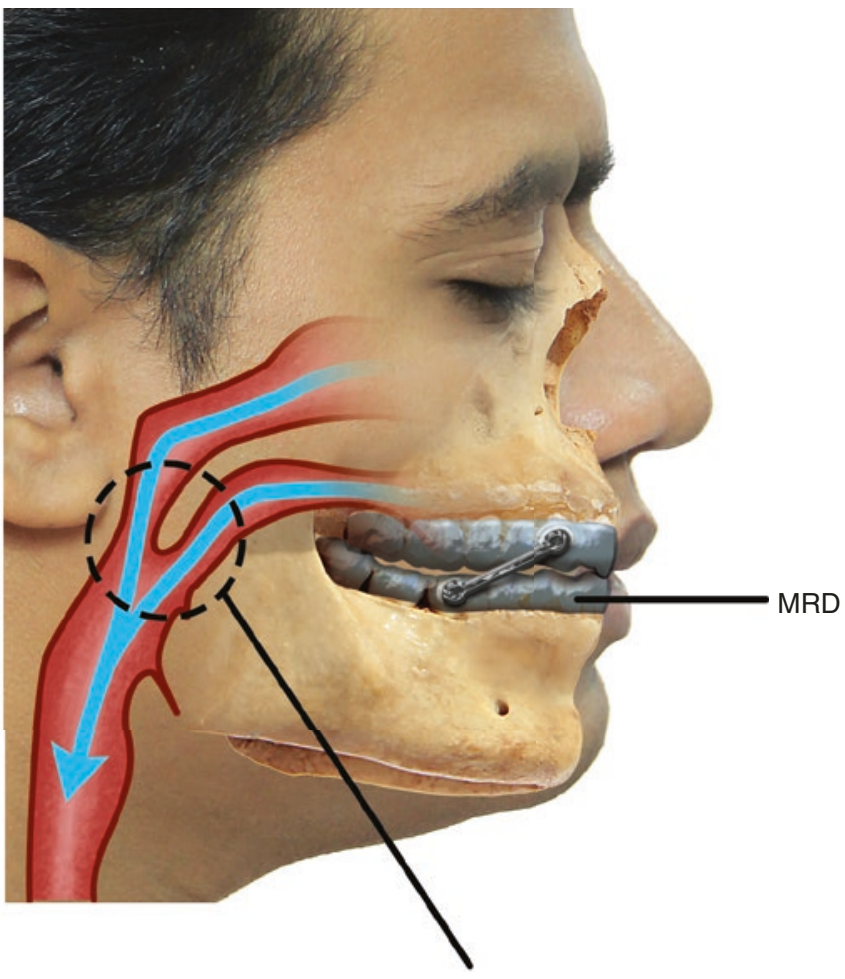

Mandibular Repositioning Device (MRD) increases airway space

Fig. 71.5 Mandibular repositioning device

Table 71.4 Common surgical procedures for OSA by site

\begin{tabular}{|c|c|}
\hline $\begin{array}{l}\text { Procedures that bypass the upper } \\
\text { airway }\end{array}$ & Tracheostomy \\
\hline \multirow[t]{6}{*}{ Nasal procedures } & Septoplasty \\
\hline & Functional rhinoplasty \\
\hline & Nasal valve surgery \\
\hline & Turbinate reduction \\
\hline & Nasal polypectomy \\
\hline & Endoscopic procedures \\
\hline \multirow{4}{*}{$\begin{array}{l}\text { Oral, oropharyngeal, and } \\
\text { nasopharyngeal procedures }\end{array}$} & uvulopalatopharyngoplasty \\
\hline & $\begin{array}{l}\text { Palatal advancement } \\
\text { pharyngoplasty }\end{array}$ \\
\hline & Tonsillectomy/adenoidectomy \\
\hline & Tori mandibularis excision \\
\hline \multirow[t]{5}{*}{ Hypopharyngeal procedures } & Tongue reduction \\
\hline & Lingual tonsillectomy \\
\hline & Genioglossus advancement \\
\hline & Hyoid suspension \\
\hline & Mandibular advancement \\
\hline \multirow[t]{2}{*}{ Laryngeal procedures } & Epiglottoplasty \\
\hline & Hyoid suspension \\
\hline \multirow[t]{2}{*}{ Global airway procedures } & $\begin{array}{l}\text { Maxillomandibular } \\
\text { advancement }\end{array}$ \\
\hline & Bariatric surgery \\
\hline
\end{tabular}

identify the target site of airway resistance cannot be over emphasized.

Tracheostomy has been used to bypasses the upper airway and is thus a successful modality in treatment, but the morbidity associated with it limits its application.

Factors in the nasal cavity may also play a role in influencing the pharyngeal stability through abnormalities like septal deviation and inferior turbinate. Nasal surgery to remove these abnormalities can improve nasal airflow, thus having a positive effect on OSA.

Multiple surgical procedures of the palate like uvulopalatopharyngoplasty (UPPP), which involves removal of the tonsils, uvula, and posterior velum in patients with large tonsils and relatively normal palatal position, are also good adjunctive procedures.

UPPP can also be done assisted by lasers allowing more precise incision and excision than conventional surgery. It also has the advantages of avoiding the need for general anesthesia and with minimal bleeding.

Tonsillectomy with adenoidectomy is the usually first line of surgery for children with OSA without significant craniofacial anomalies. 


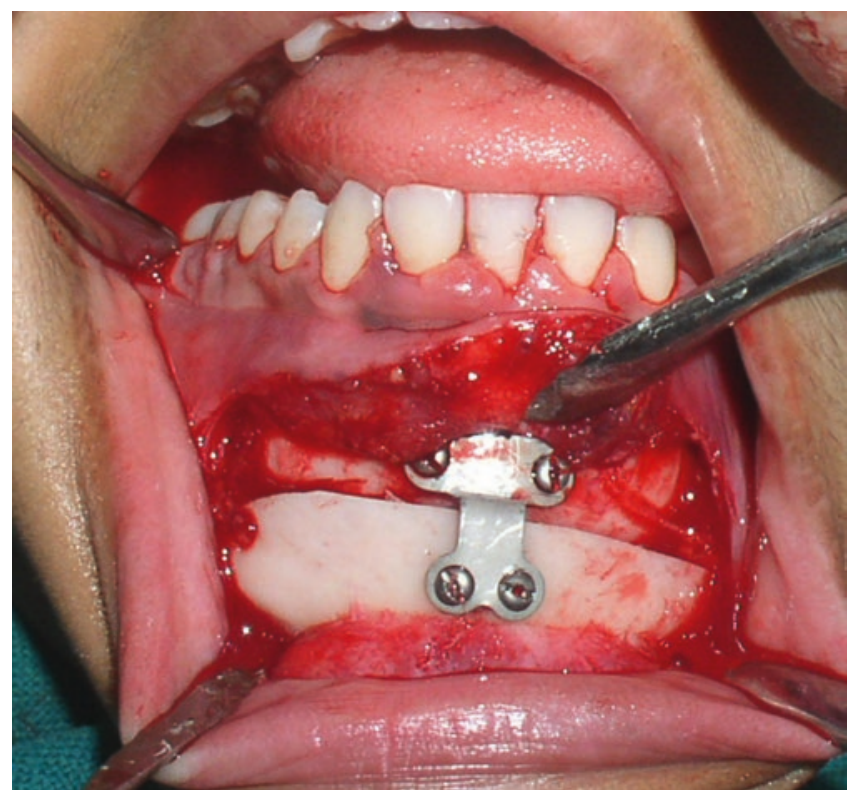

CAssociation of Oral and Maxillofacial Surgeons of India

Fig. 71.6 Genioglossal advancement

Tongue reduction is also a part of the surgical option in enlarges tongue cases where partial glossectomy can reduce the tongue volume.

Surgical procedures of the genial segment of the mandible like Genioglossal advancement moves the genial tubercles forward along with the genioglossus muscle, resulting in a more forwardly positioned base of tongue. In addition, it also causes the forward movement of the hyoid bone. This shift increases the posterior airway space and avoids the collapse of its walls during the REM phase of sleep. There are a lot of modifications of the genial advancement procedures.

The standard procedure moves the whole genial segment including the chin. A modified technique allows the surgeon to advance the genial tubercle without altering the normal anatomic position or shape of a patient's chin by only moving the rectangular bony component involving the tubercle (Fig. 71.6).

Hyoid myotomy involves the detachment of infrahyoid muscles and moving the hyoid forward and upward and fixing it with sutures. Another procedure moves the hyoid forward and downward with excision of the lesser cornu and fixing the hyoid anterior to the thyroid cartilage by sutures.

Surgical procedures can also be performed at different levels either concomitantly or in a staged manner. This is done when patients have more than one site of obstruction.

Hypoglossal nerve stimulators (HGNS) are a new addition to the armamentarium for treatment of OSA. It was approved by the FDA for treatment of moderate to severe OSA in 2014 [22].
The device which acts like a pacemaker monitors the breathing patterns and gets activated during sleep to stimulate the hypoglossal nerve, thus controlling upper airway muscles.

Maxillomandibular advancement (MMA) is undoubtedly the most successful surgical technique in OSA. This advantage of this procedure is the effect in correcting airway obstruction at multiple levels. The surgical advancement of the maxillomandibular skeletal framework corrects the airway collapsibility at the nasopharyngeal and oropharyngeal levels and is ideal in patients with moderate and severe OSA who exhibit multilevel obstruction.

The Le Fort I osteotomy of the maxilla along with mandibular sagittal split osteotomy is performed for advancing maxilla and mandible, thus increasing the airway space as it draws the base of the tongue and soft palate forwards (Fig. 71.7).

Achieving MMA by distraction is another alternative technique, especially in cases of TMJ ankylosis (Figs. 71.8 and 71.9) where a deficient mandible in the sagittal plane is primarily responsible for the obstructed airway.

The dimensions of maxilla and mandible can also be increased in the transverse plane by distraction resulting in increase in the dimensions of nasopharynx, oropharynx, and the nasal cavity along with movement of tonsillar pillars and the musculature of the velum. Maxillomandibular transverse distraction osteogenesis can be concomitantly be performed with their sagittal advancement for a more effective form of treatment MMA alone.

\subsection{Adjunctive Therapies}

\subsubsection{Bariatric Surgery [23]}

Weight loss procedures through bariatric surgery is indicated in patients with a body mass index (BMI) $\geq 40 \mathrm{~kg} / \mathrm{m}^{2}$ or those with a BMI $\geq 35 \mathrm{~kg} / \mathrm{m}^{2}$ with important comorbidities especially when dietary attempts are ineffective.

\subsubsection{Medications [23]}

Pharmacologic agents can on occasion be used with some degree of success in treating OSA by increasing glossopharyngeal neurologic activity or decreasing REM sleep.

Protriptyline, a tricyclic antidepressant reduces the frequency of apnea and desaturation in non-REM sleep and suppressing REM activity. It also increases the tone of the upper airway muscles. The anticholinergic activity of the drug however limits its use. 

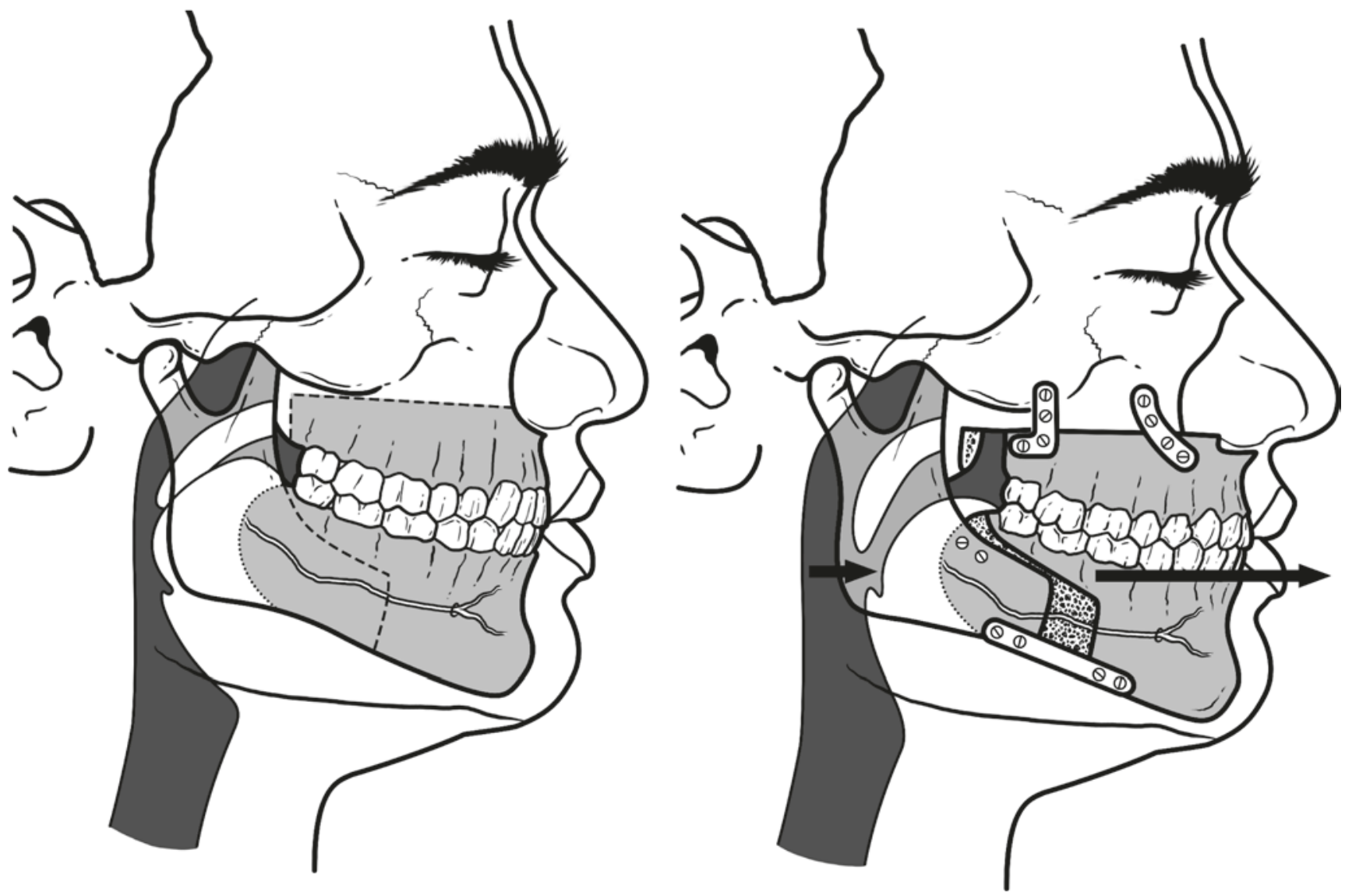

CAssociation of Oral and Maxillofacial Surgeons of India

Fig. 71.7 Maxillomandibular advancement and its effect on the airway

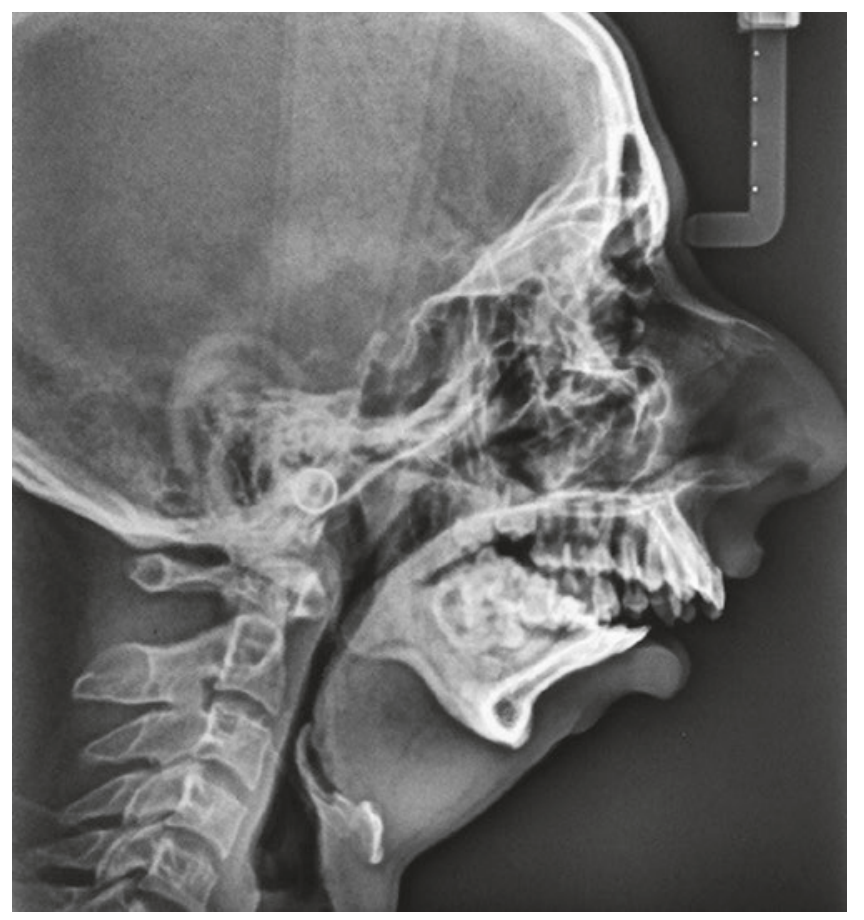

CAssociation of Oral and Maxillofacial Surgeons of India

Fig. 71.8 Compromised airway in ankylosis

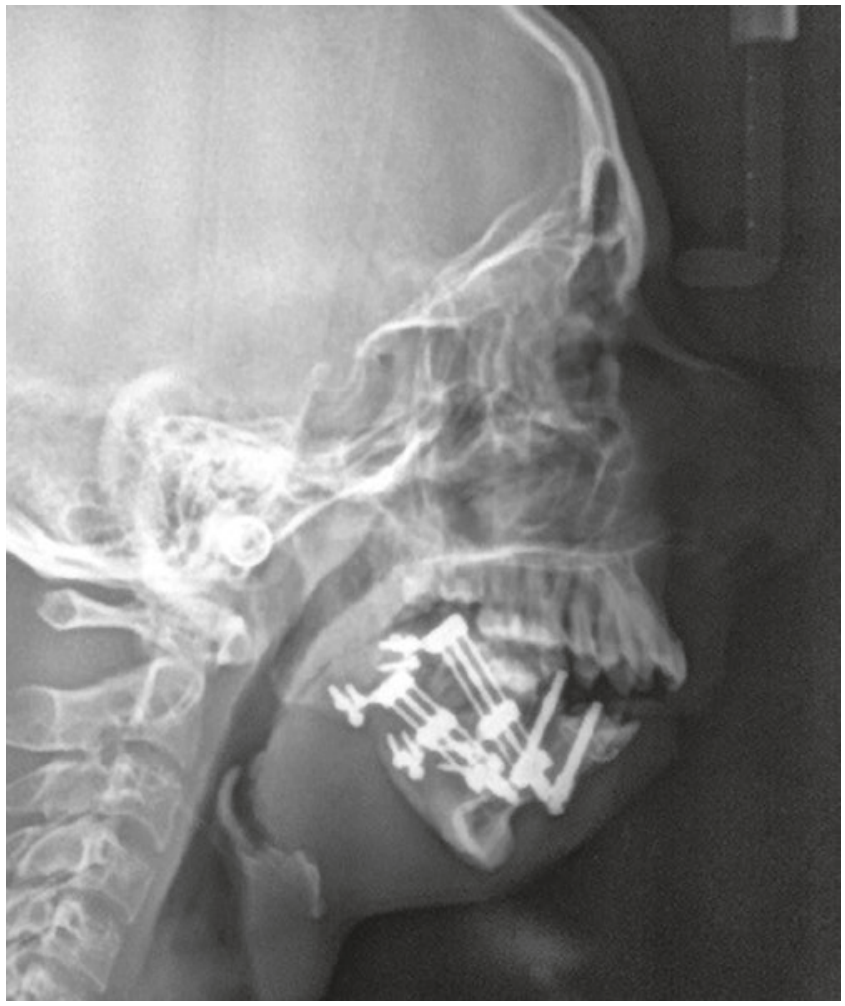

CAssociation of Oral and Maxillofacial Surgeons of India

Fig. 71.9 Improved airway after mandibular distraction in a TMJ ankylosis case 
Theophylline reduces the episodes of apneas and hypopneas, but the quality of sleep deteriorates.

Modafinil is a wake-promoting medication that can improve residual daytime sleepiness in OSA patients despite regular use of CPAP. It is however avoided in patients who are noncompliant with CPAP. The adverse effects of these drugs are headache and nervousness.

Topical nasal corticosteroids have also been recommended in patients suffering from concurrent rhinitis.

\subsection{Conclusion}

Obstructive sleep apnea is a multi-factorial and multi-level condition whose management needs to be customized for every patient after a correct diagnosis. Treatment is regulated starting with the non-surgical options and moving to specific site surgical procedures depending on the area of involvement.

\subsection{Case Scenario}

A 12-year-old female patient with history of sleeping difficulty due to airway obstruction.

Clinical features: Retruded chin, incompetent lips, dry mouth, short chin throat distance (Fig. 71.10).

Preoperative radiographic findings: Deficient mandible, posteriorly placed menton, narrowed oropharynx (Fig. 71.11).

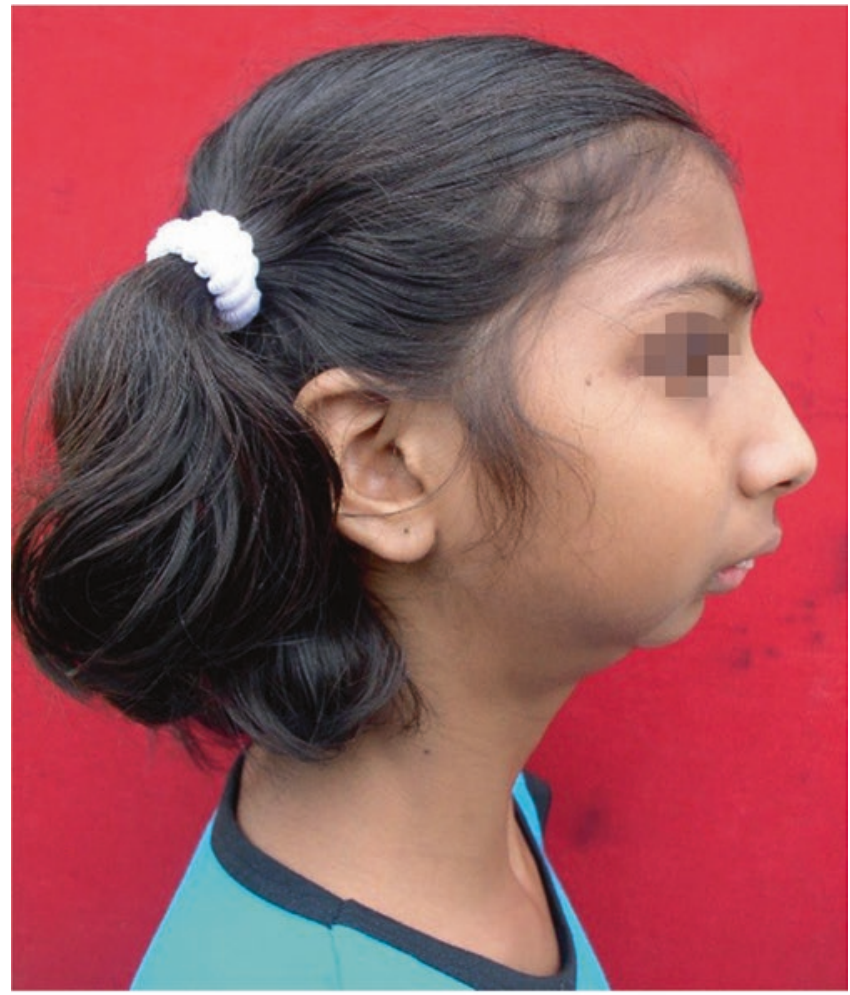

CAssociation of Oral and Maxillofacial Surgeons of India

Fig. 71.10 Patients profile
PSG report: Episodes of 33 apneas and 76 hypopneas confirming OSA (Box 71.1).

Treatment plan: Mandibular advancement of $10 \mathrm{~mm}$ by distraction (Fig. 71.12).

Post op findings: Improved profile, no episodes of apneas hypopneas (Figs. 71.13, 71.14 and Box 71.2).

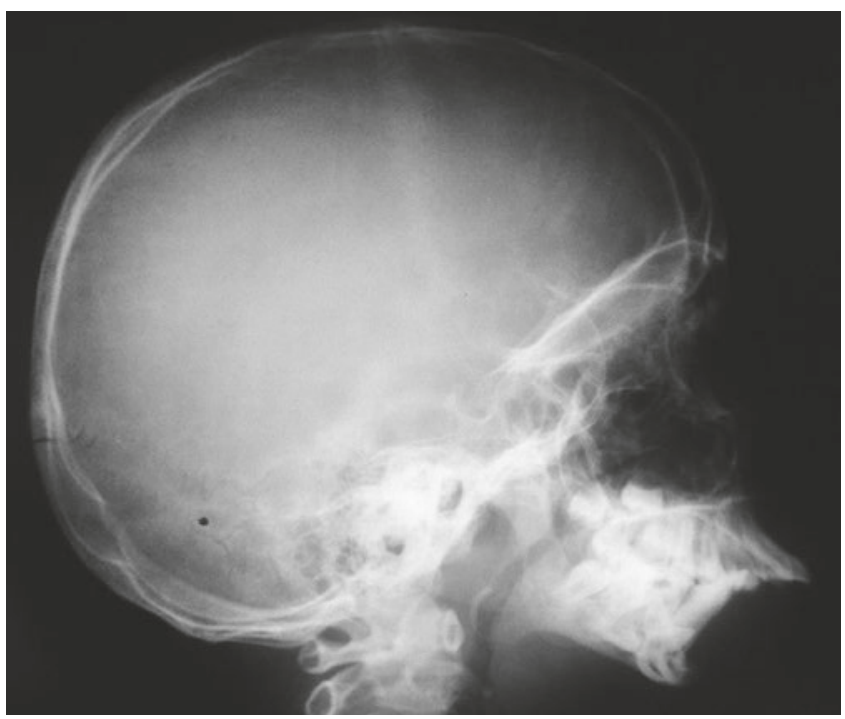

CAssociation of Oral and Maxillofacial Surgeons of India

Fig. 71.11 Preoperative cephalogram

Box 71.1 Preoperative PSG report

\begin{tabular}{|l|l|}
\hline Events & Number \\
\hline Apnoeas & 33 \\
\hline Hypopnoeas & 76 \\
\hline
\end{tabular}

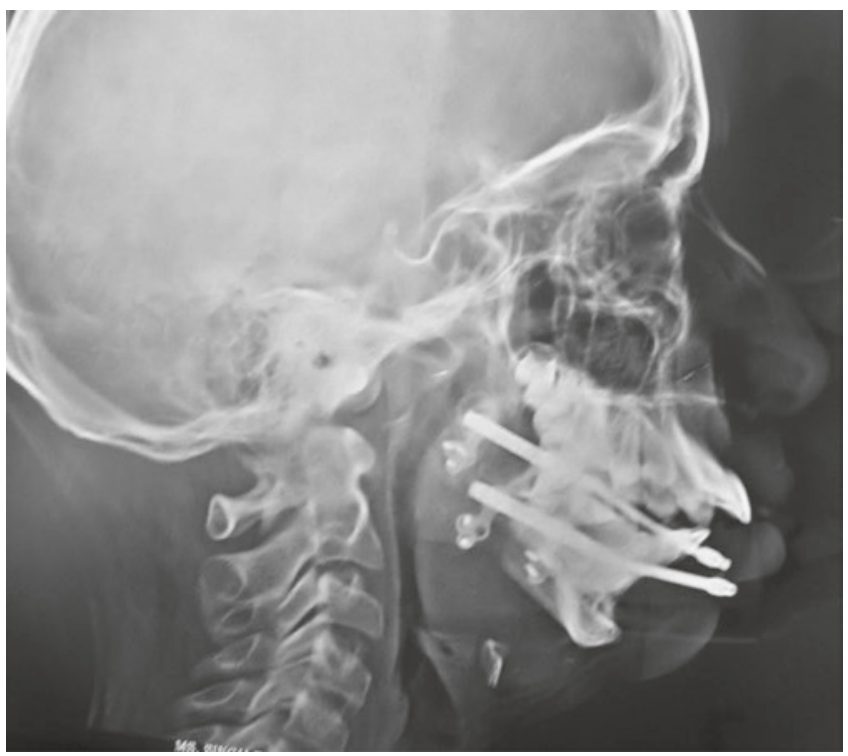

CAssociation of Oral and Maxillofacial Surgeons of India

Fig. 71.12 Mandibular distraction 


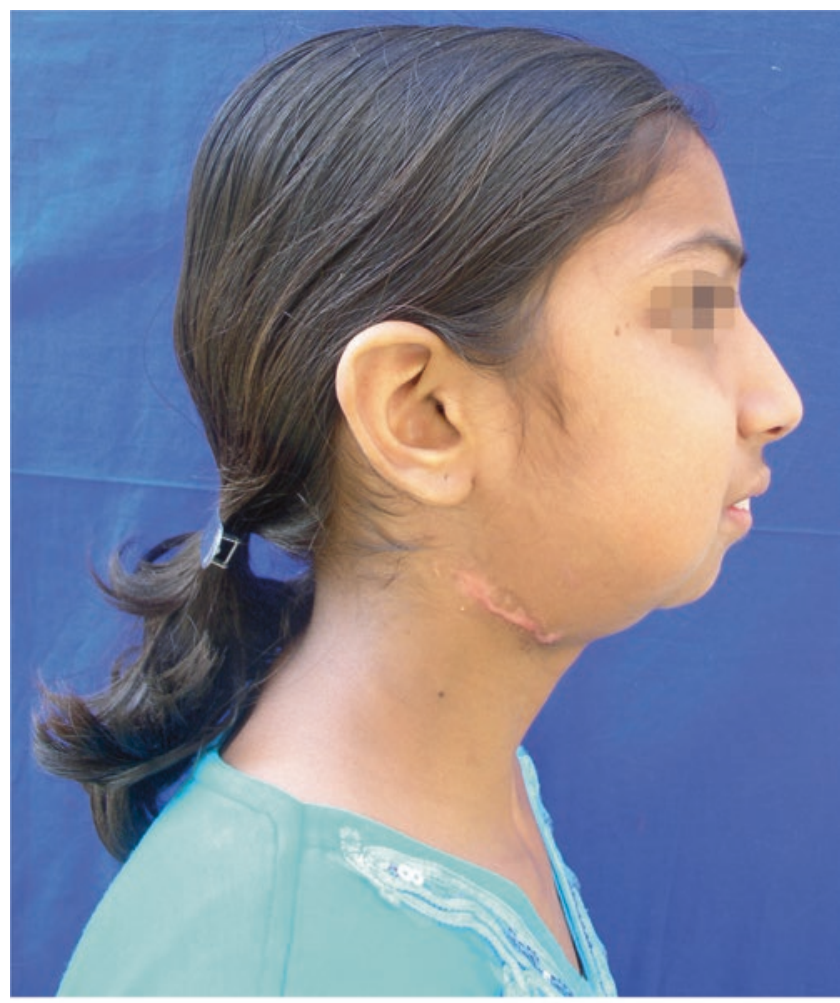

CAssociation of Oral and Maxillofacial Surgeons of India

Fig. 71.13 Postoperative profile of the patient

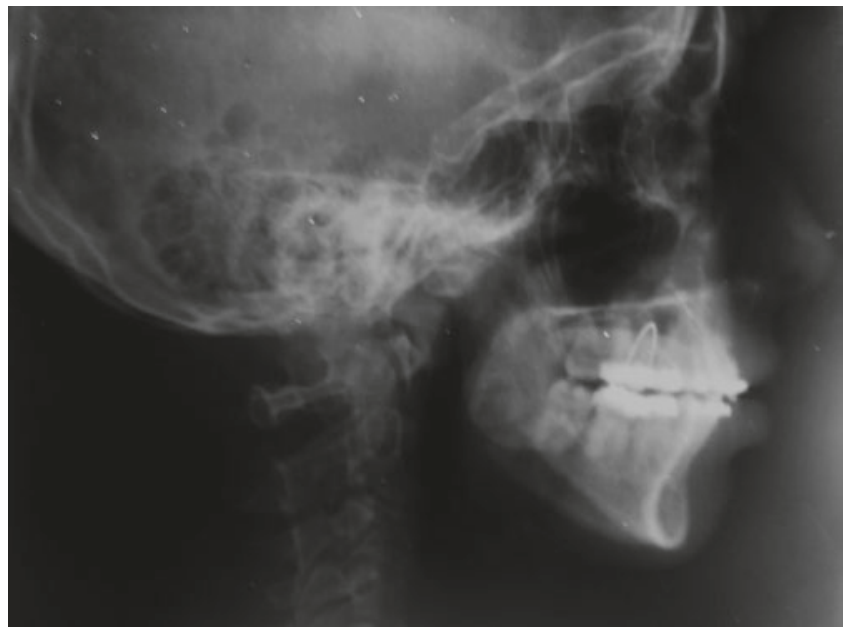

CAssociation of Oral and Maxillofacial Surgeons of India

Fig. 71.14 Postoperative cephalogram showing improved airway

Box 71.2 Post distraction PSG report

\begin{tabular}{|l|l|}
\hline Events & Number \\
\hline Apnoeas & 0 \\
\hline Hypopnoeas & 0
\end{tabular}

\section{References}

1. Epstein LJ, Kristo D, Strollo PJ, Friedman N, Malhotra A, Patil SP, et al. Clinical guideline for the evaluation, management and longterm care of obstructive sleep apnea in adults. J Clin Sleep Med. 2009 Jun 15;5(3):263-76.

2. Susarla SM, Thomas RJ, Abramson ZR, Kaban LB. Biomechanics of the upper airway: changing concepts in the pathogenesis of obstructive sleep apnea. Int J Oral Maxillofac Surg. 2010;39:1149-59.

3. Carolyn C, Brookes D, Boyd SB. Controversies in obstructive sleep apnea. Surg Oral Maxillofac Surg Clin N Am. 2017;29:503-13.

4. Javaheri S, Barbe F, Campos-Rodriguez F, Dempsey JA, Khayat $\mathrm{R}$, Javaheri S, et al. Sleep apnea types, mechanisms, and clinical cardiovascular consequences. J Am Coll Cardiol. 2017;69(7): $841-58$.

5. Kaur A, Mokhlesi B. The effect of OSA therapy on glucose metabolism: it's all about CPAP adherence! J Clin Sleep Med. 2017 Mar 15;13(3):365-7.

6. Yee B, Liu P, Phillips C, Grunstein R. Neuroendocrine changes in sleep apnea. Curr Opin Pulm Med. 2004 November;10(6):475-81.

7. Young T, Palta M, Dempsey J, Skatrud J, Weber S, Badr S. The occurrence of sleep disordered breathing among middle aged adults. N Engl J Med. 1993;328:1230.

8. Young T, Peppard PE, Gottlieb DJ. Epidemiology of obstructive sleep apnea. Am J Respir Crit Care Med. 2002;165:1217.

9. Kim S-J, Kim Y-S, Park J-H, Kim S-W. Cephalometric predictors of therapeutic response to multilevel surgery in patients with obstructive sleep apnea. J Oral Maxillofac Surg. 2012;70: 1404-12.

10. Tangugsorn V, Krogstad O, Espeland L, Lyberg T. Obstructive sleep apnoea: multiple comparisons of cephalometric variables of obese and non-obese patients. J Cranio Maxillofac Surg. 2000;28:204-12.

11. Gotsopoulos H, Kelly JJ, Cistulli PA. Treatment of OSA oral appliance therapy reduces blood pressure in obstructive sleep apnea: a randomized, controlled trial. Sleep. 2004;27(5):934-41.

12. Herford AS, Finn R. Single-stage CO2 laser assisted uvuloplasty for treatment of snoring and mild obstructive sleep apnoea. J Cranio-Maxillofac Surg. 2000;28:213-6.

13. Barbick MB, Dolwick MF. Genial tubercle advancement and sleep apnea. J Oral MaxillofacSurg. 2009;67:1767-70.

14. Sullivan C, Berthon-Jones M, Issa F. Nocturnal nasal-airway pressure for sleep apnea. N Engl J Med. 1983;309:112.

15. Li KK, Riley RW, Powell NB, Troell RJ. Obstructive sleep apnea surgery: Genioglossus advancement revisited. J Oral Maxillofac Surg. 2004;59:1181-4.

16. Foltan R, Hoffmannova J, Pretl M, Donev F, Marek VLK. Genioglossus advancement and hyoid myotomy in treating obstructive sleep apnoea syndrome - a follow-up study. J CranioMaxillofac Surg. 2007;35:246-51.

17. de Ruiter MHT, Apperloo RC, Milstein DMJ, de Lange J. Assessment of obstructive sleep apnoea treatment success or failure after maxillomandibular advancement. Int J Oral Maxillofac Surg. 2017;46:1357-62.

18. Scott Conleya R, Leganb HL. Correction of severe obstructive sleep apnea with bimaxillary transverse distraction osteogenesis and maxillomandibular advancement. Am J Orthod Dentofac Orthop. 2006;129:283-92.

19. Louro RS, Calasans-Maia JA, Mattos CT, Masterson D, CalasansMaia MD, Maia LC. Three-dimensional changes to the upper airway after maxillomandibular advancement with counterclockwise rotation: a systematic review and meta-analysis. Int J Oral Maxillofac Surg. 2018;47:622-9. 
20. Jayan B, Prasad BNBM, Bhattacharya D, Rajput AK, Dhiman RK. Management of a case of severe obstructive sleep apnoea with acrylic Herbst splint appliance: a case report Indian. J Sleep Med. 2006;1(3):157-60.

21. Fleisher KE, Krieger AC. Current trends in the treatment of obstructive sleep apnea. J Oral Maxillofac Surg. 2007;65:2056-68.

22. Hochban W, Podszus T, Eisele DW, Schwarz AR, Smith PL, Erickson D, Testerman R. Hypoglossal nerve stimulation for obstructive sleep apnoea. Int J Oral Maxillo fac Surg. 1997;26:156.

23. W Keith Thornton and D Heath Roberts. Non-surgical management of the Obstructive sleep apnea patient. J Oral Maxillofac Surg. 1996;54:1103-8.

\section{Suggested Reading}

Carolyn C. Dicus Brookes, Scott B. Boyd: Controversies in Obstructive Sleep Apnea Surgery. Oral Maxillofacial Surg Clin N Am 29 (2017) 503-513.

Kasey K Li: Maxillomandibular advancement for Obstructive Sleep Apnea. J Oral Maxillofac Surg 69:687-694, 2011.

Lawrence J. Epstein, David Kristo, Patrick J. Strollo, Norman Friedman, Atul Malhotra, Susheel P. Patil et al. Clinical Guideline for the Evaluation, Management and Long-term Care of Obstructive Sleep Apnea in Adults. J Clin Sleep Med. 2009 Jun 15; 5(3): 263-276.

Open Access This chapter is licensed under the terms of the Creative Commons Attribution 4.0 International License (http://creativecommons. org/licenses/by/4.0/), which permits use, sharing, adaptation, distribution and reproduction in any medium or format, as long as you give appropriate credit to the original author(s) and the source, provide a link to the Creative Commons license and indicate if changes were made.

The images or other third party material in this chapter are included in the chapter's Creative Commons license, unless indicated otherwise in a credit line to the material. If material is not included in the chapter's Creative Commons license and your intended use is not permitted by statutory regulation or exceeds the permitted use, you will need to obtain permission directly from the copyright holder. 